\title{
Multiple targets operation of reservoir group in flood-season in the Yangtze River
}

\author{
Li Anqiang \\ Changjiang Institute of Survey, Planning, Design and \\ Research \\ Wuhan, China, 430010 \\ hxc_hust@163.com
}

\begin{abstract}
China has built many reservoirs in the Yangtze River. Those reservoirs play an important role in flood control, electricity generation and shipping. But it is difficult to operation reservoir group reasonably because the comprehensive utilization demand. Especially in flood-season, there are usually many different targets to be considered. This paper researched the multiple targets operation of reservoir group in flood-season in the Yangtze River by multi-objective evaluation method. Three reservoir group operation schemes were selected to be compared. The results show that scheme three is the best scheme which has the highest evaluation value. The method this paper proposed is effective in comparing and selecting schemes in flood control management.
\end{abstract}

Keywords- multiple targets, reservoir group, reservoir operation in flood-season, the Yangtze River, scheme evaluation

\section{INTRODUCTION}

The Yangtze River is about $6300 \mathrm{~km}$ long and has a drainage basin area of $1.80 \times 106 \mathrm{~km} 2$ [1]. It's the longest river in China and the third in the world in terms of length and discharge [2].

In order to security the cities in the middle and downstream from flood in flood-season and better use water resource, China has built many reservoirs in the Yangtze River. Those reservoirs play an important role in flood control, electricity generation, and shipping and so on [3]. It is difficult to operation reservoir group reasonably because the comprehensive utilization demand. Especially in floodseason, there are usually many different flood control object to be considered, at the same time, the storage rates and electric energy production are also important.

It is difficult to compare each other because there are different metrics and units among different reservoirs operation targets [4]. And usually it is contradict to achieve those targets, such as the reservoirs storage more water, it is benefit to electricity generation and agricultural irrigation, but it is disadvantageous to flood control for downstream in flood-season. So it is necessary to synthesize each kind of targets in order to select the best schemes which one has the best benefits of reservoir group operation.

It will be helpful to compare and evaluation reservoir operation schemes and provide decision support for reservoirs operation by researching multiple targets operation of reservoir group in flood-season.

\author{
He Xiaocong \\ Changjiang Institute of Survey, Planning, Design and \\ Research \\ Wuhan, China, 430010 \\ muzi7632@sina.com
}

\section{STUDY AREAS}

The flood in the Yangtze River is mainly in the upstream and middle stream, flooded areas are Jingjiang area and Dongting Lake area in the middle stream, where representative hydrologic stations are Zhicheng hydrologic station and Chenglingji hydrologic station [5]. In this paper 11reserviors are selected in the middle and upstream areas of Yangtze River to research the jointly reservoirs operation flood control strategy, and the protective goals are Zhicheng hydrologic station and Chenglingji hydrologic station [6]. The reservoirs and hydrological stations selected can be seen in Figure 1. The main features of every reservoir are shown in Table 1.

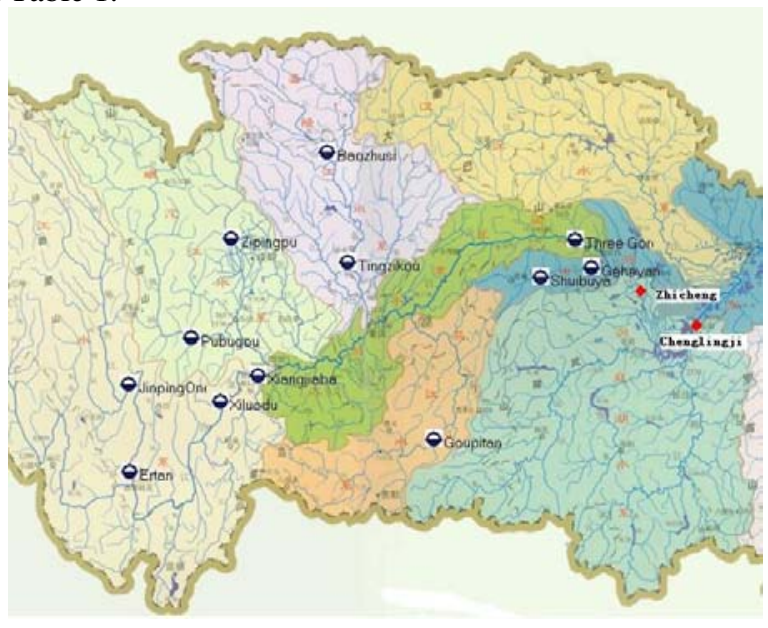

Figure 1. Reservoirs and hydrologic stations research selected

TABLE I. MAIN FEATURES OF RESERVOIR SELECTED

\begin{tabular}{|c|c|c|c|}
\hline $\begin{array}{c}\text { Reservoir's } \\
\text { name }\end{array}$ & $\begin{array}{c}\text { Catchment } \\
\text { area } \\
\left(\mathbf{1 0}^{\mathbf{4}} \mathbf{k m}^{\mathbf{2}} \mathbf{)}\right.\end{array}$ & $\begin{array}{c}\text { Flood control } \\
\text { storage } \\
\left(\mathbf{1 0}^{\mathbf{8}} \mathbf{m}^{\mathbf{3}}\right)\end{array}$ & $\begin{array}{c}\text { Total } \\
\text { storage } \\
\left(\mathbf{1 0}^{\mathbf{8}} \mathbf{m}^{\mathbf{3}}\right)\end{array}$ \\
\hline Three Gorges & 100 & 221.5 & 445.7 \\
\hline Jinping One & 10.26 & 16 & 77.6 \\
\hline Ertan & 11.64 & 9 & 58 \\
\hline Xiluodu & 45.44 & 46.5 & 129.14 \\
\hline Xiangjiaba & 45.88 & 9.03 & 51.63 \\
\hline
\end{tabular}




\begin{tabular}{|c|c|c|c|}
\hline Pubugou & 6.851 & 15 & 50.6 \\
\hline Zipingpu & 2.266 & 1.67 & 11.12 \\
\hline Baozhusi & 2.843 & 2.8 & 25.5 \\
\hline Goupitan & 4.325 & 4 & 55.64 \\
\hline Shuibuya & 1.086 & 5 & 45.8 \\
\hline Geheyan & 1.443 & 5 & 37.7 \\
\hline
\end{tabular}

It need to protect many flood-protect areas of reservoirs operation in the Yangtze River in flood season, such as medium and large cities from Yibin and Chongqing, Zhicheng areas, Chenglingji area, Dongting Lake and Poyang lake. Therefore protect Zhicheng and Chenglingji areas from flood damage is the primary of reservoirs operation in the up and middle stream of the Yangtze River basin. At the same time, in order to satisfy water resource requirements in non-flood seasons, such as power generation and agricultural irrigation, the reservoirs should be fill-up with water. So, there are three flood season operation targets in reservoirs in the up and middle stream of the Yangtze River basin, which are low flood discharge in Zhicheng area, low flood discharge in Chenglingji area and high storage rates of reservoirs.

\section{Mythology}

According to the general decision method of multiobjective problem, the multiple targets operation of reservoir group in flood-season can divide into structure decision matrix, give objects attribute value; determine weight of object; scheme evaluation.

\section{A. Structure decision matrix}

Decision matrix is the basis to solve multi-objective decision problem. Set $\mathrm{A}_{i}(i=1,2, \ldots, m)$ is the scheme $i$, and $\mathrm{X}_{j}(j=1,2, \ldots, n)$ is the target $j$, then the decision problem can be formulate as a decision matrix $\mathrm{R}$.

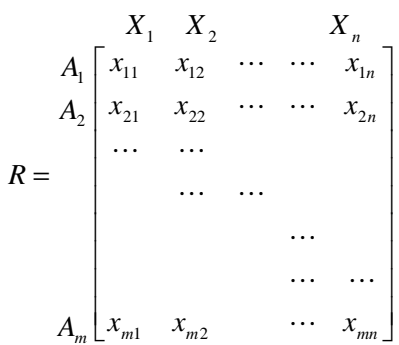

The element $x_{i j}$ in decision matrix $R$ is the attribute value of scheme $i$ to the target $j$. Attribute values of every scheme structured the decision matrix, which is also called attribute values table [7].

\section{B. Give objects attribute value}

Different attribute values have different measure units in the decision matrix, which need to be standardization so as to remove different measure units' influence to decision. The (0-1) interval domain transformation method can be used to standardization evaluation targets.
For profit type attribute, set

$$
r_{i j}=\frac{x_{i j}-x_{j \min }}{x_{j \max }-x_{j \min }}
$$

For cost type, set

$$
r_{i j}=\frac{x_{j \min }-x_{i j}}{x_{j \max }-x_{j \min }}
$$

\section{C. (3) Determine weight of object}

The evaluation targets is not equal importance in decision problems, so it has to determine the relative importance of different targets, which is usually express as weights of targets [8]. If there were $n$ targets in a multiobjective decision-making problem, the weight of target $\mathrm{i}$ is wi, then the weight matrix $\mathrm{W}$ is:

$$
W=\left[\begin{array}{cccc}
W_{1} & & & \\
& w_{2} & & \\
& & \ddots & \\
& & & w_{n}
\end{array}\right]
$$

The close to ideal point method can be used to calculate scheme evaluation, which import distance to consider the distance to ideal scheme and negative ideal scheme. The main idea is suppose a ideal scheme and a negative ideal, and then calculate the distance from scheme calculated to ideal scheme, and the distance from scheme calculated to negative ideal scheme. The best scheme is nearest to ideal scheme and farthest to negative ideal scheme. Here the distance is weighted Euclidean distance.

Structure weighted attribute matrix

$$
V=R \cdot W=\left[\begin{array}{cccc}
r_{11} w_{1} & r_{12} w_{2} & \cdots & r_{1 n} w_{n} \\
r_{21} w_{1} & r_{22} w_{2} & \cdots & r_{2 n} w_{n} \\
\vdots & \vdots & \ddots & \vdots \\
r_{m 1} w_{1} & r_{m 2} w_{2} & \cdots & r_{m n} w_{n}
\end{array}\right]
$$

Calculating Euclidean distance

$$
\begin{gathered}
S_{i}^{*}=\sqrt{\sum_{j=1}^{n}\left(v_{i j}-v_{j}^{*}\right)^{2}} \\
S_{i}^{-}=\sqrt{\sum_{j=1}^{n}\left(v_{i j}-v_{j}^{-}\right)^{2}}
\end{gathered}
$$

Here, $S_{i}^{*}$ is the distance to ideal scheme, and $S_{i}^{-}$is the distance to negative ideal scheme.

Calculating the relative close degree 


$$
C_{i}=\frac{S_{i}^{-}}{S_{i}^{-}+S_{i}^{*}} \quad(i=1,2, \ldots, \mathrm{m})
$$

The value of $C_{i}$ is bigger, the scheme is better.

\section{SCHEME EVALUATION OF RESERVOIRS OPERATION}

\section{A. Evaluation objects and weights}

In the multiple targets operation of reservoir group in flood-season in the Yangtze River, Zhicheng flood, Chenglingji flood and reservoirs storage are chosen as evaluation indexes. The name and type of those indexes are shown in Table 2. The weights in the table are determined by expert knowledge, which can be changed in the actual operation situation.

TABLE II. EVALUATION OBJECTS AND WEIGHTS

\begin{tabular}{|c|c|c|c|c|}
\hline Target name & Type & $\begin{array}{c}\text { Best } \\
\text { value }\end{array}$ & Max value & weight \\
\hline Zhicheng flood & cost & 0 & 100 & 0.6 \\
\hline Chenglingji flood & cost & 0 & 500 & 0.2 \\
\hline Three Gorges storage & profit & 221.5 & 221.5 & 0.1326 \\
\hline Jinping One storage & profit & 16 & 16 & 0.0096 \\
\hline Ertan storage & profit & 8.55 & 8.55 & 0.0051 \\
\hline Xiluodu storage & profit & 46.5 & 46.5 & 0.0278 \\
\hline Xiangjiaba storage & profit & 9.03 & 9.03 & 0.0054 \\
\hline Pubugou storage & profit & 15 & 15 & 0.0090 \\
\hline Zipingpu storage & profit & 1.67 & 1.67 & 0.0010 \\
\hline Baozhusi storage & profit & 2.6 & 2.6 & 0.0016 \\
\hline Goupitan storage & profit & 3.44 & 3.44 & 0.0021 \\
\hline Shuibuya storage & profit & 4.97 & 4.97 & 0.0030 \\
\hline Geheyan & profit & 4.89 & 4.89 & 0.0029 \\
\hline
\end{tabular}

\section{B. Scheme and operation results}

In this paper, three schemes are used to compare the operation benefit, their parameters shown in Table 3.

TABLE III. PARAMETERS OF USED SCHEMES

\begin{tabular}{|c|c|c|c|c|}
\hline \multirow{2}{*}{$\begin{array}{c}\text { Scheme } \\
\text { number }\end{array}$} & \multicolumn{2}{|c|}{ Three Gorges reservoir } & \multicolumn{2}{c|}{ Others reservoir } \\
\cline { 2 - 5 } & $\begin{array}{c}\text { Zhicheng and } \\
\text { chegnglingji }\end{array}$ & $\begin{array}{c}\text { Only } \\
\text { Zhicheng }\end{array}$ & $\begin{array}{c}\text { Zhicheng } \\
\text { and } \\
\text { chegnglingji }\end{array}$ & $\begin{array}{c}\text { Only } \\
\text { Zhicheng }\end{array}$ \\
\hline One & $25 \%$ & $84 \%$ & $80 \%$ & $100 \%$ \\
\hline Two & $45 \%$ & $85 \%$ & $80 \%$ & $100 \%$ \\
\hline Three & $45 \%$ & $85 \%$ & $100 \%$ & $100 \%$ \\
\hline
\end{tabular}

Statistics the operation results of the three schemes, the table 4 shows flood distage in Zhicheng and Chenglingji.

\section{Scheme evaluation}

Evaluation the three operation schemes according to the close to ideal point calculation method (Table 5).

TABLE V SCHEME EVALUATION RESULTS

\begin{tabular}{|c|c|c|c|}
\hline flood & Scheme one & Scheme two & Scheme three \\
\hline $1931(1 \%)$ & 0.8319 & 0.8637 & 0.8989 \\
\hline $1935(1 \%)$ & 0.8237 & 0.8363 & 0.9192 \\
\hline $1954(1 \%)$ & 0.8764 & 0.8879 & 0.8931 \\
\hline $1968(1 \%)$ & 0.891 & 0.908 & 0.9214 \\
\hline $1969(1 \%)$ & 0.8076 & 0.8285 & 0.8842 \\
\hline
\end{tabular}

\begin{tabular}{|c|c|c|c|}
\hline $1980(1 \%)$ & 0.8817 & 0.9537 & 0.9679 \\
\hline $1983(1 \%)$ & 0.9186 & 0.9372 & 0.9504 \\
\hline $1988(1 \%)$ & 0.8695 & 0.9096 & 0.9312 \\
\hline $1996(1 \%)$ & 0.8954 & 0.9146 & 0.9245 \\
\hline $1998(1 \%)$ & 0.8842 & 0.9084 & 0.8482 \\
\hline average & 0.868 & 0.895 & 0.914 \\
\hline
\end{tabular}

Form the average evaluation values by the 10 floods in Table 5 we can see that scheme three is best, and scheme two is better, and scheme three is worst. Compares the results of scheme one and three, the flood in scheme three is lower than scheme one in every year. Compares the results of scheme two and three, the flood in scheme three is lower than scheme two in all years except 1998. In 1998, the flood in Zhicheng in scheme three is $1.78 \times 108 \mathrm{~m} 3$ bigger than scheme two, but the flood in Chenglingji is $97.18 \times 108 \mathrm{~m} 3$ lower than scheme two. That is to say in the scheme three the Zhicheng endure a small amount of flood can greatly reduce flood in Chenglingji area. So the scheme three is the best scheme.

\section{CONCLUSIONS}

Reservoir group flood-season operation has the characteristic of large-scale, wide-range, multiple targets and at great position in national economy. The scheduling efficiency is complex and difficult to evaluate in operation group management. The multiple targets flood control operation evaluate methods of reservoir group this paper proposed is effective in comparing and selecting schemes in flood control management, especially massive and complicated reservoir group. And provide a new and effective method for flood control management and the decision making basis for reservoir group operation.

\section{ACKNOWLEDGEMENT}

This work was financially supported by the National Key Technology R\&D Program for the 12th five-year plan. Project no. 2012BAB04B05-4.

\section{REFERENCES}

[1] Eunchang Lee. Large Engineering Project Risk Management Using a Bayesian Belief Network[J]. Expert Systems with Applications, 2009, 36(3):5880-5887.

[2] Su Wei, Zhang Xiaodong, Wang Zhen, et al. Analyzing disaster-forming environments and the spatial distribution of flood disasters and snow disasters that occurred in China from 1949 to 2000. Mathematical and computer modelling. 2011, 54(3-4) : 1069-1078.

[3] Usitalo L. Advantages and Challenges of Bayesian Networks in Environmental Modelling[J]. Ecological Modelling, 2007, 203(3/4):312-318.

[4] Ren J. An Offshore Risk Analysis Method Using Fuzzy Bayesian Network[J]. Journal of Offshore Mechanics and Arctic Engineering, 2009, 131(4):1101-1112.

[5] Zhang Qiang, Xu Chongyu, Becker Stefan, Jiang Tong. Sediment and runoff changes in the Yangtze River basin during past 50 years. Journal of Hydrology. 2006, 331 : 511523.

[6] Chang L C, Chang F J. Intelligent control for modeling of real-time reservoir operation [J]. Hydrological Processes, 2001,15(9):16211634. 
[7] Li Xungui, Wei Xia. An improved genetic algorithm-simulated annealing hybrid algorithm for the optimization of multiple reservoirs[J]. Water Resources Management, 2008, 22(8):1031-1049.
[8] Peng C S, Buras N. Practical estimation of inflows into multireservoir system [J]. Journal of Water Resources Planning and Management, 2000, 126(5):331-334.

TABLE IV. OPERATION RESULTS OF THREE SCHEMES

\begin{tabular}{|c|c|c|c|c|c|c|}
\hline \multirow{2}{*}{$\begin{array}{c}\text { Flood } \\
\mathbf{( 1 \% )}\end{array}$} & \multicolumn{2}{|c|}{$\begin{array}{c}\text { Scheme one flood } \\
\left(\mathbf{1 0}^{\mathbf{8}} \mathbf{~ m}^{\mathbf{3}} \mathbf{)}\right.\end{array}$} & \multicolumn{2}{c|}{$\begin{array}{c}\text { Scheme two flood } \\
\left(\mathbf{1 0}^{\mathbf{8}} \mathbf{m}^{\mathbf{3}} \mathbf{)}\right.\end{array}$} & \multicolumn{2}{c|}{$\begin{array}{c}\text { Scheme three flood } \\
\left(\mathbf{1 0}^{\mathbf{8}} \mathbf{~ m}^{\mathbf{3}} \mathbf{)}\right.\end{array}$} \\
\cline { 2 - 7 } & Zhicheng & Chenglingji & Zhicheng & Chenglingji & Zhicheng & Chenglingji \\
\hline 1931 & 0.00 & 354.89 & 0.00 & 278.07 & 0.00 & 266.9 \\
\hline 1935 & 0.00 & 374.77 & 0.00 & 341.95 & 0.00 & 335.5 \\
\hline 1954 & 0.00 & 249.56 & 0.00 & 223.76 & 0.00 & 212.77 \\
\hline 1968 & 0.00 & 216.65 & 0.00 & 179.89 & 0.00 & 173.44 \\
\hline 1969 & 0.00 & 417.34 & 0.00 & 362.97 & 0.00 & 349.79 \\
\hline 1980 & 0.00 & 131.13 & 0.00 & 87.20 & 0.00 & 79.22 \\
\hline 1983 & 0.00 & 156.74 & 0.00 & 110.20 & 0.00 & 106.85 \\
\hline 1988 & 0.00 & 219.62 & 0.00 & 176.25 & 0.00 & 173.72 \\
\hline 1996 & 0.00 & 206.06 & 0.00 & 164.59 & 0.00 & 145.77 \\
\hline 1998 & 0.00 & 232.25 & 0.00 & 179.75 & 17.8 & 163.49 \\
\hline
\end{tabular}

